\title{
Socio-demographic Characteristics of Drowning Cases Recorded At a Tertiary Care Hospital
}

\author{
Chowdhury $\mathrm{MH}^{1}$, Rahman $\mathrm{MM}^{2}$, Hosasain $\mathrm{MG}^{3}$, Islam $\mathrm{MR}^{4}$
}

\begin{abstract}
Background: The autopsy diagnosis of drowning represents one of the major problems in forensic medicine. Objective: The purpose of the present study was to see the socio-economic characteristics of the drowning cases. Methodology: It was a retrospective study of 20 cases of drowning in 13 thanas of Dinajpur district during 1st January 2004 to December 2006. All the cases were autopsied in the mortuary of Dinajpur Medical College, Dinajpur. All the above may show signs of immersion on examination. Result: Total 20 cases were brought to the Department of Forensic Medicine at Dinajpur Medical College, Dinajpur. Considering the socio-economic status of the victim, it is found that higher frequency of drowning in the lower socio-economic growth. Highest age group is present in the 0-10 years which is 4 cases, 5 cases and 4 cases in the year of 2004, 2005 and 2006 respectively. Conclusion: In the conclusion, the study reveals that majority drowning cases are from low socio-economic condition with an early age group.
\end{abstract}

Keywords: Asphyxia, drowning, autopsy

\section{Introduction}

Drowning is a form of asphyxial death when the respiratory passage is occupied by fluid or water, due to submersion under water and inhalation of water. It is a common occurrence in our country to be drowned, it is not necessary that the whole body should be under water. Submersion of mouth and nasal opening by any means is sufficient for that purpose $^{1}$.

In a classical case of drowning, full submersion does not occur all at a time. The mean specific gravity of the body is less than that of water. It is due to the buoyancy of the body that a person can float or swim on water. Drowning literally means death by submersion in water or in any other liquid because of being unable to breathe whereas submersion or immersion means putting or plugging the person under water. Drowning denotes a confined concept where death is due to submersion in water or in any other fluid. Water immersion or submersion conveys a broader concept when death might have been due to drowning or some other cause $^{2}$. Now-a-days different papers publish the incidence of drowning with great importance although many cases have not been reported due to social stigma and prestige of the family. Drowning is two types like fresh water drowning and salt water drowning. In fresh water drowning death is probably due to hypoxia and haemodilution, follwed by cardiac arrhythmia leading to ventricular tachycardia and fibrillation. In sea water drowning water is drawn from the blood into lung tissue and producing severe edema and hypernatraemia due to high salinity of sea water (usually over $3 \% \mathrm{NaCl}$ ), which causes hemo-concentration. A marked bradycardia occurs probably due to raised plasma sodium level and slow death occurs from asphyxia ${ }^{3}$.

The causes of drowning are swimmer exhaustion or other adversities. Due to ignorance of swimming and due to fear and apprehension, the victim of drowning first swallows and intakes water and thus the air in the lungs is gradually replacing the water. These increase the weight of the body which ultimately submerges totally under the water surface. When the victim cries for help, a good amount of air comes out from the lungs. With the attempt of inspiration, some water comes in contact with the laryngeal opening and cough reflex occur and thus a part of the reserved air from the lungs also comes out. Simultaneously, as the victims engulfs some water, the weight of the body further increases. Ultimately the mean specific gravity of the body becomes more than that of the water, which leads to final submersion. This is the period of extreme agony and fright for the victim till he/she loses consciousness. The aim of the present study was to observe the socio-demographic status of the drowning patients.

1. Dr. Md. Habibuzzaman Chowdhury, Associate Professor, Department of Forensic Medicine, Shaheed Suhrawardy Medical College, Dhaka

2. Dr. Md. Mizanur Rahman, Associate Professor, Department of Forensic Medicine, Enam Medical College, Dhaka

3. Dr. Md. Gisan Hossain, Lecturer, Department of Forensic Medicine, Enam Medical College, Dhaka

4. Prof. Md. Rafiqul Islam, Professor, Department of Microbiology, Shaheed Suhrawardy Medical College, Dhaka

\section{Correspondence}

Dr. Md. Habibuzzaman Chowdhury, Associate Professor, Department of Forensic Medicine, Shaheed Suhrawardy Medical College, Dhaka-1207, Bangladesh; Cell No.: +8801711593558 


\section{Methodology}

This was a retrospective study which was carried out from January 2004 to December 2006. During this time all the medico-legal cases were referred to the Department of Forensic Medicine at Dinajpur Medical College, Dinajpur from different police stations of Dinajpur district which is located 278 kilometers north-west of Dhaka. The data was collected from the relatives of the victims. Data were analyzed in the SPSS statistical program.

\section{Results}

Total 20 cases were brought by 13 police stations and one railway station for medico-legal examination to the Department of Forensic Medicine at Dinajpur Medical College. According to police statistics the highest frequency were from Kotowaly thana and lowest from Hakimpur thana. The cases of the drowning victim were noted according to socio-economic condition (table 1). Considering the socio-economic status of the victim, higher frequency of drowning is found in the lower socio-economic group which is $13(65.0 \%)$ cases.

Table 1: Distribution of cases according to socioeconomic status

\begin{tabular}{lcccc}
\hline Class & $\begin{array}{c}\text { No. of cases } \\
(\mathbf{2 0 0 4 )}\end{array}$ & $\begin{array}{c}\text { No. of cases } \\
(\mathbf{2 0 0 5})\end{array}$ & $\begin{array}{c}\text { No. of cases } \\
(\mathbf{2 0 0 6 )}\end{array}$ & Total \\
\hline Upper & $1(25.0)$ & $2(50.0)$ & $1(25.0)$ & $4(100.0)$ \\
Middle & $1(66.7)$ & $2(33.3)$ & $0(0.0)$ & $3(100.0)$ \\
Lower & $4(30.8)$ & $4(30.8)$ & $5(38.4)$ & $13(100.0)$ \\
Total & $\mathbf{6 ( 3 0 . 0 )}$ & $\mathbf{8 ( 4 0 . 0 )}$ & $\mathbf{6 ( 3 0 . 0 )}$ & $\mathbf{2 0 ( 1 0 0 . 0 )}$ \\
\hline
\end{tabular}

*Figure in the parenthesis indicates percentage.

The age group was noted in table 2. Highest age group is present in the $0-10$ years which is $4(30.8 \%)$ cases, $5(38.4 \%)$ cases and $4(30.8 \%)$ cases in the year of 2004, 2005 and 2006 respectively. The trend of drowning cases is increased from 2004 to 2006 which is $6(30.0 \%)$ cases and $7(35.0 \%)$ cases respectively.

Table 2: Distribution of cases according to the age

\begin{tabular}{ccccc}
\hline $\begin{array}{c}\text { Age group } \\
\text { (Years) }\end{array}$ & $\begin{array}{c}\text { No. of cases } \\
(\mathbf{2 0 0 4 )}\end{array}$ & $\begin{array}{c}\text { No. of cases } \\
(\mathbf{2 0 0 5 )}\end{array}$ & $\begin{array}{c}\text { No. of cases } \\
(\mathbf{2 0 0 6 )}\end{array}$ & Total \\
\hline $0-10$ & $4(30.8)$ & $5(38.4)$ & $4(30.8)$ & $13(100.0)$ \\
$11-20$ & $1(25.0)$ & $1(25.0)$ & $2(50.0)$ & $4(100.0)$ \\
$20-30$ & $2(66.7)$ & $1(33.3)$ & $0(0.0)$ & $3(100.0)$ \\
Total & $\mathbf{7 ( 3 5 . 0 )}$ & $\mathbf{7 ( 3 5 . 0 )}$ & $\mathbf{6 ( 3 0 . 0 )}$ & $\mathbf{2 0 ( 1 0 0 . 0 )}$ \\
\hline
\end{tabular}

*Mean age $\pm \mathrm{SD}=8.3 \pm 5.86$ years

*Figure in the parenthesis indicates percentage.

The most common autopsy findings among the study population are recorded. During autopsy all 20(100.0\%) cases have shown wet body and cloths, presence of mud and sand over the body, persistent copious fine leathery white froth from mouth and nasal opening, mud and sand in esophagus, stomach and intestine and voluminous, edematous balloon like lungs.

Table 3: Most Common autopsy findings among the study population $(n=20)$

\begin{tabular}{lcc}
\hline Findings during Autopsy & Frequency & Percentage \\
\hline Wet body and cloths & 20 & 100.0 \\
Presence of mud \& sand on body & 20 & 100.0 \\
Copious fine leathery white froth & 20 & 100.0 \\
Lungs voluminous, edematous & 20 & 100.0 \\
Presence of mud and sand in GIT & 20 & 100.0 \\
\hline
\end{tabular}

*GIT: Gastrointestinal tract

\section{Discussion}

Drowning is a form of asphyxial death which is seen frequently in this country and rare in other countries of the world ${ }^{4}$. Drowning is usually divided into two major types like typical drowning and atypical drowning ${ }^{3}$. Typical drowning is also known as wet drowning in which there actual obstruction of air passages by the fluid or water column is entering into it. In atypical drowning there is very little or no fluid or water which is inhaled into air passages. It includes four sub types like dry drowning, immersion syndrome, submersion of unconsciousness, secondary drowning that is near drowning syndrome ${ }^{4}$.

A total number of 20 cases were brought by 13 police stations and one railway station for medico-legal examination to the Department of Forensic Medicine at Dinajpur Medical College, Dinajpur. According to police statistics the highest frequency were from Kotowaly thana and lowest from Hakimpur thana. The reason may be the presence of more ponds in these areas. The cases of the drowning victim were noted according to socio-economic condition. Considering the socio-economic status of the victim, higher frequency of drowning is found in the lower socio-economic group which is $13(65.0 \%)$ cases. The reason of more victims in this socio-economic status may be due to bathing in the pond water which is due to lack of shower in their houses.

Highest age group is present in the $0-10$ years which is $30.8 \%$ cases, $38.4 \%$ cases and $30.8 \%$ cases in the year of 2004, 2005 and 2006 respectively. In this age group drowning is the most common. The trend of drowning cases is increased from 2004 to 2006 which is $30.0 \%$ cases to $35.0 \%$ cases respectively. The reason is lack of knowledge to swim in the water. However, negligence of toddlers is also responsible for this. Important issue regarding drowning case is to diagnose which is a very difficult task. Bodies retrieved from water may have died from natural disease before falling in water or died from natural disease while already in water. However, death from injury before being thrown into water or death due to injury while in water may also occur. In these cases the diagnosis can be done by taking history, the condition of clothing, mud and sands over the body. Autopsy finding usually depends on the delay, both in recovering of the body from the water and in 
starting the post mortem examination. When a considerable period has elapsed between death and retrieval of the body, the positive signs of drowning progressively fade. Depending on temperature, a period of several days in the water is likely to minimize most changes. However, once significant putrefaction has occurred than apart from the controversial diatom test, there is little hope of finding positive signs of drowning ${ }^{5}$.

The signs of submersion in a dead body recovered from the water for the same period are wet body and cloths, presence of mud and sand over the body. Persistent copious fine leathery white froth has been found in mouth and nasal opening which is a vital finding in case of death due to drowning. However mud and sand are also found in esophagus, stomach and intestine on dissection. The lungs are found voluminous, edematous balloon like and appearance with marks of indentation over the surface by ribs. The lungs pit on pressure. Diatoms which are unicellular algae are found in some remote organ and tissues including brain and bone marrow. There are changes in blood chemistry like increased chloride and potassium ion in fresh water drowning; on the other hand decreased sodium level, magnesium may be increased in salt water drowning. In case of froth from mouth and nostril it is persistent and copious in drowning whereas it is not so in putrefaction and some poisoning cases.

\section{Conclusion}

In the conclusion the features of drowning are interesting and divergent from person to person as narrated by some of the victims after being rescued and resuscitated. Some has given the felling of dullness with total lethargy and unconscious. Some has given a painless felling with memory of events which are very remote past and interesting. Drowning is really a form of asphyxial death which can be checked and prevented by being alert and conscious.

\section{References}

1. Nandi A. Principles of forensic Medicine including Toxicology; Violent asphyxial death, Page- 640

2. Viz K. Text Book of Forensic Medicine \& Toxicology, asphyxial death Page-176

3. Reddy KSN. The Essentials of Forensic Medicine \& Toxicology by, 28th edition, Mechanical asphyxia Page -322

4. Rao NKG. Text Book of Forensic Medicine \& Toxicology, 2nd edition; Violent asphyxial death, page-214

5. Knight B. Forensic Pathology, 2nd edition; Immersion death Page -399 